a large right multilocular tumour, and twelve years before Dr. Granville Bantock, at the Samaritan Hospital, London, removed one from the other side.

One of the most instructive cases of the series was that of a woman aged forty years, an inmate of the Belper Workhouse, sent to me by Mr. Allen. She had been tapped fourteen times for ascites, the last within a fortnight of her admission into hospital last April. So quickly had reaccumulation taken place that then her abdomen was much distended, and through the fluid could be felt, at the lower third of the abdomen, a fixed resistant mass, which per vaginam could be felt filling up the pelvic cavity. It was decided to open the abdomen, when the papillomatous nature of the growth revealed itself; and at first, on account of its adhesions, it was thought to be quite impossible to enucleate it, but nltimately this was done and an elastic ligature thrown round its base to control the very free hæmorrhage. The growth was then cat off, when it was found that what had seemed one homogeneous mass was in reality two growths springing from both ovaries which had met in the middle and overlapped the uterus. The stump was therefore disinfected, as in an ordinary hysterectomy, and treated extra-peritoneally, with the result that the patient made a very good recovery and has remained in perfect health ever since. ${ }^{4}$ In treating the pedicle in the four supra-vaginal hysterectomies for fibroids the intra-peritoneal method was used in one case, and tying off the arterial supply and fixing the stump to the parietes, or what is known as the "mixed method," in the other three.

In the matter of the removal of the aterine appendages for inflammatory disease no operation was performed without ample justification in the clinical symptoms and local conditions of the case, supplemented, when necessary, by an examination under an anæsthetic, and also acquainting those concerned with the immediate and remote effects of the operation. Now one word as to the place of exploratory incisions in this branch of surgery. No hard-and-fast line can be laid down in this matter, inasmuch as what wovid be rash because dangerous in the hands of one surgeon is in the hands of another a safe and reasonable evolution of diagnostic methods. In saying this $I$ am far from wishing to anderrate the gravity of the procedure, bnt, whilst granting this, it seems to me that when we have exhausted all other available aids to diagnosis, and either completely or in some material point failed, or when with a full knowledge of the pathology of the case there is a doubt as to its operable character, then we are perfectly justified, after stating the nature and limits of the proposed operation, in counselling those concerned to run the very slight risk which is involved. I need hardly say that at such a time one ought to be prepared to undertake whatever operation the exigencies of the case demands, so that no one should perform an exploratory operation without being perfectly familiar with the technique of abdominal surgery.

Nottingham.

\section{ON CYCLING AS A CAUSE OF HEART DISEASE.}

BY GEORGE HERSCHELL, M.D. LOND.

PHYSICIAN TO THE NATIONAT, HOSPITAL FOR DISEASES OF THE HEART, SOHO SQUARE.

An Abstract of a Paper communicated to the Eighth International Congress of Hygiene and Demography, Budapest, 1894

Tнस chief danger of cycling, or rather the reason why it may become more injurious than some other forms of exercise, is the fact that a cyclist takes much more exercise than he is aware of, and is very frequently tempted to overtax his powers. He starts off in the morning for a ride fresh and vigorous, having previously mapped out his course; but when the time arrives for his midday meal he may have some few miles yet to go. He has perbaps over-rated his capacity; or the condition of the roads renders it impossible to travel at the rate upon which he had based his calculations. But he is hungry, and so he redoubles his efforts to reach his destination and when he arrives there he is utterly fagged out and has lost his appetite. As an example of the facility

4 Feb. 26th, 1895: This patient still keeps well, having had no reurrence. with which one may be lead into taking more exertion than one has counted upon I may relate a case which came under my notice a few weeks ago. A gentleman who had not ridden for some time started out one morning for a run into the country, neglecting to take any lamp. When he arrived at his destination it came on to rain, and the friends whom he was visiting prevailed upon him to stay until late in the evening. At half-past seven he found himself still fifteen miles from home, and on that particular evening police regulations compelled the lamps to be lighted at a quarter past eight. It was now a race against time, but he succeeded in reaching home only a few minutes after that hour. I saw him at nine o'clock. His pulse was then 125, and he complained of thirst, restlessness, and a feeling of oppression at the chest. At 9.15 his pulse was 120 . At ten it was 110 , At eleven o'clock it had sunk to 100 . He then retired to bed, but passed a sleepless night. On rising in the morning his pulse was 90, and it did not reach the normal 68 until the day after. The commonest way, however, in which the cyclist injures himself is in climbing hills. He is nearing the top of the hill, and the heart is dilated with the strain put upon it by the increased arterial tension. If the rider were now to stop and recover himself no harm would be done. But in too many cases he sees that only a few more revolutions of the wheel will be required to carry hin to the top. So he redoubles his exertions, putting further strain upon a heart already taxed to the utmost limit of its capacity, and in those few moments damage has been done to the heart from which it perhaps cannot recover.

$I$ believe that it is usual at the commencement of a olub ran for the riders to agree that they will adapt their pace to the slowest member. That is all very well in theory, but what really takes place is that after a time one of the faster riders unconsciously quickens his pace. The rest of the clab follow suit, and before very long they are all travelling at a rate which is far beyond the capacity of a certain proportion of the set. To be unable to keep up with the rest of the clab is a confession of effeminacy, and it would be morally impossible to get of your machine and walk up a hill which your friends are riding up. Another circumstance which increases the deadli. ness of the modern cycle is the fact that it is nowadays considered a point of honour, especially among novices, to ride with as high a gear as possible. It is, I am sure, no exaggeration to say that 90 per cent. of all riders are using a gear much too high for their strength. For the benefit of those who are not practical cyclists I will here explain what is meant by "gear." In the early days of cycling the pedals were attached directly to the axis of the driving wheel. The effect of this was that the largest wheel which could be used was determined by the length of the legs of the rider. And since the distance which a machine would travel with one revolution of the pedals depended upon the size of the wheel, tall men were at a great advantage over short ones when it came to racing. So every one rode as large a wheel as he conld, and strictured uretbra from perineal pressure was common. The introduction of geared machines altered all this. The pedals, instead of being attached to the hub of the driving wheel, communicate motion to a cog-wheel, and this in its turn, by means of a chain or other mechanical device, rotates another wheel rigidly fastened to the hub of the driving wheel. $\mathrm{Br}$ varying the sizes of the respective wheels the driving whee can be caused to rotate a greater number of times than the pedals. If, therefore, a driving wheel of thirty inches in diameter were caused to rotate twice for every once that the pedals went round, you would be securing all the advantage of a sixty.inch wheel as regards speed with half the weight Of course the more a machine is geared up the harder work it is to push it. That is what is meant by a high gear Machines for racing are geared up to seventy inches or more Boys of fifteen or sixteen years of age boast that they ride machines geared up to sixty-three inches, whereas a fifty-six inch gear would be much more suitable for them.

The subject-matter of this paper is intended to apply to the thousands of every-day cyclists. I am not taking into consideration the path and road racers. These men are deliberately sacrificing their future bealth for the sake of winning a few prizes. What shall we say to 460 miles ridden in twenty-four hours at Herne Hill last year? A this race some of the men rode until they dropped ot their machines. Another very reprehensible thing is what is known as a "hill-climbing contest." Everything that have said with regard to riding up bills applies here with double force. Hills of the steepest gradient are purposely 
selected, and the competitors ride up them against time, trying to break existing records for that particular hill. Nothing more suicidal or more certain to produce heart disease can possibly be imagined.

The effects upon the heart of the strain of excessive cycling may be divided into four groups :-1. Simple hypertrophy of the heart. 2. Acute dilatation of the heart, ending either in recovery if the cause be removed or in death if it persists. 3 Chronic valvular disease of the heart. 4. Functional derangement of the heart.

Grodp 1.-Simple Hrpertrophy of THE Hrant.

This is apt to occur in well-trained riders who do a great deal of cycling, and may be looked upon as a compensatory effort of nature to enable the work to be performed. Cycling for extended periods of time at a great pace, like other forms of prolonged muscular exertion, enormously increases the blood pressure in the arteries. Hypertrophy of the heart follows the law which governs all muscles-that increased work is followed by increased growth if the nutrition is kept up. Moderate degrees of hypertrophy are quite compatible with health, and are usually unattended with symptoms. The danger, however, is in the ultimate effects which are liable to ensue. The heightened blood pressure in the arteries gradually produces a hard inelastic condition of their walls, which perpetuates and increases the hypertrophy. Moreover, these altered arteries are prone sooner or later to undergo degenerative changes, and, having lost their normal elasticity, to gire way on some occasion of sudden strain. As a rule, the athlete enjoys vigorous health for the few years during which he is actively working, and his heart is only enlarged enough to meet the constant demands upon it; but when the cyclist, no longer in his first youth and unable to compete with younger men, relaxes his efforts, his heart is now too large for the work it is required to do, and the symptoms of hypertrophy soon make themselves felt. Hypertrophy following over-exertion may disappear under proper treatment if taken early and the cause removed, but when it has persisted for a number of years this is rarely, if ever, possible, and ulterior changes are apt to ensue. It is well known that athletes are liable to rapid deterioration of health when they relinquish their active exercises. It is also probable that a hypertrophied heart may undergo degenerative changes whilst in active daily work. This is rendered probable by what is known to happen in the case of filecutters, whose work consists in quickly flexing their biceps The effect of this is to cause hypertropby of that muscle, but after a few years it atrophies. This is so certainly known in the trace that file-cutters receive very high wages, based upon the probable working life of their hypertrophied biceps. It is possible that in this way we may have an explanation of the well-known fact that compensatory hypertrophy of the heart cannot be preserved indefinitely, although the valve lesion may be stationary. Hypertrophy of the heart produced by cycling may terminate in one of these ways (1) recovery ; (2) valvular disease and disease of the aorta; (3) degeneration of the heart muscle.

Group 2.-ACUTe Diuatation of THE Heart. Until the individual first shows signs of being "out of breath" both ventricles are sending equal quantities of blood into the pulmonic and aortic systems respectively in equal periods of time. At each beat the left heart is withdrawing from the lungs exactly the same quantity of blood that has been forced into them by the right heart. And it is evident that the oxygen supplied to the blood is exactly equal to what the body requires. Respiration and the heart's action, although hurried by the exercise, are carried on cormally and without unpleasant sensations. If, however, the exercise be continued, the heart is stimulated to contract at such a rate that the respiratory muscles cannot keep pace with it. Besides, the time during which it is possible for the blood to come into contact with the oxygen in the lungo is shortened. "Shortness of breath" is thus produced, the sensation being, as we all know, the cry of the blood for more oxggen. Accompanying this will be obstruction to the circulation through the lungs, and a small abnormal amount of residual blood will remain in the right ventricle. If the extreme muscular efforts are continued the excess of venous blood in the pulmonary vessels will increase with every beat and the right heart will rapidly dilate. At this stage th quantities of blood thrown out from the two ventricles are unequal. The heart continues beating and expelling the whole of its contents with the exception of the residual blood in the right rentricle. At last a moment comes when rom fatigue the muscles at the base of the ventricles are no onger able to adapt the ring to which the bases of the valves are attached so that the valves will efficiently olose them. And since the whole of the valvalar ring is expanded while the valves have retained their former size regurgitation must take place. If at this point the individual ceases his muscular efforts, in all probability the heart will quickly recover itself; but if the recovery is not complete there may remain permanent incompetence of the tricuspid valve. On the other hand, if the exertion is kept up, the heart, being unable to pass on the whole quantity of blood that reaches it at each beat, undergoes rapid dilatation of the right ventricle and death by asystole is the result. Of such a character doubtless are the cases of sudden heart failure which has occasionally caused the death of riders even in the course of a journey. The following fatal case of acute overstraining of the heart occasioned by cycling came under my notice in 1884, and the notes may be of interest as showing the symptoms which may be expected. A man aged forty-six years had lately taken to cycling and used a heavy tricycle. After having followed the sport for three weeks and made some short journeys he attempted to ride from Brighton, where be resided, to London, a distance of fifty-three miles. I was called to see bim about seven o'clock in the evening at his hotel and found him cyanosed and very exhausted. There was intense dyspnoea, and his pulse was 144 per minute and very feeble. His heart's action was irregular and weak. Dulness extended transversely from a quarter of an inch outside the right parasternal line to the left mammary line. The apex was beating in the sixth intercostal space in the left mammary line. A systolic bruit was apparent both over the mitral and tricuspid areas, and there was pulsation in the veins of the neck. The urine contained a trace of albumen Unfortunately, in spite of treatment, he gradually sank, and died early next morning. I was informed that the patient had never previously exhibited any symptoms which pointed to heart disease. The absence of marked hypertrophy of the heart would also negative the supposition. No post.mortem examination could be obtained. The case was evidently one of acute dilatation of the heart in a man not so young as to be able to undertake with impunity such a muscular task as a ride of fifty-three miles against time. The overstrained and distended heart was unable to contract vigorously enough to restore the equilibrium, and fatal syncope was the result. Acute dilatation of the heart produced by cycling, then, may terminate either-(1) in recovery ; or (2) in the production of valvular disease.

\section{Group 3.-Chronic Valyular Disease of the Heart.}

I believe that the mechanism by which permanent valvalar disease of the heart is produced by overstrain from exercises such as cycling is twolold: 1 . As a sequel to acute dilatation of the heart. The ring to which the bases of the auriculoventricular valves are attached having been once stretched sufficiently to allow regurgitation to take place does not recover itself, but remains permanently enlarged. We shall thus have regurgitation into the auricle. The case will then pass through the usual stages of compensatory hypertrophy, with probably final breaking down of compensation. 2. As a result of hypertrophy. It is probable that the constant high tension in the arterial system with the resulting strain upon the valves occasions slight injuries to their surface with the subsequent production of sclerotic changes. In cases which have come under my notice I have found that the great majority suffered from lesions of the aortic valves, and I have reason to believe that the hypertrophy always ante-dated the valve mischitf. This is only what we might expect. The aorta, unlike the heart, cannot strengthen itself against an excescive strain, as its activity is practically nothing more than the recoil of elastic tissue. Strain of such a structure will cause chronic endarteritis and loss of elasticity. If you examine such an artery with a microscope you will find small points of endarteritis upon the inner coat and patches of diffase granular exudation in the middle one. The next step will be dilatation or pouching of the aorta just above the valves which are as yet competent. Many cases come under observation in this condition, and the following may be taken as a typical example. A man thirty-one years of age attended my out-patient department at the hospital in the autumn of 189?. He complained of palpitation and shortness of breath. Daring the summer he had been constantly riding the bicycle, going on an average sixty miles a day for three days a week. On examination there was evident bypertroply of the heart, the apex beating 
in the anterior axillary line. The right margin of cardiac dalness was half an inch to the right of the sternum. The arterial dulness over the upper edges of the sternum was decidedly wider than it should be, pointing to dilatation of the aorta. There were no bruits and no thrills, bat there was marked accentuation of the aortic second sound. This would probably be the first stage in the production of valvalar disease. As regards the further course of such a case we have three possibilities : (1) the aortic ring may be stretched by the pouching of the aorta and regurgitation may take place; (2) a valve may actually give way ; (3) sclerotic changes may take place in the valves. In any of these cases the disease will follow the usual course of valvular mischief produced by other causes.

\section{Group 4.- Hunditonal Derangement of The Heart.}

I believe that this condition as the result of cycling is much more common than is generally supposed. Many cases are but slight and quickly recover, so that they are overlooked or ascribed to other causes. Da Costa applied the term "irritable heart" to chronic cases of tachycardia which he observed amongst the men engaged in the American Civil War. This condition resembled in many respects the functional affections of the heart which we see as the result of strain when cycling. It is extremely probable that they are identical as regards pathology. I believe that these conditions always follow a temporary dilatation of the heart in the following manner. As we have shown, right-sided dilatation of the heart is invariably produced by the prolonged strain of too rapid cycling. This dilatation having subsided when the canse has ceased to operate, the heart remains irritable from the stretching that its muscular fibres have undergone. It would seem in these cases almost as if the inhibitory function of the pneumogastric nerve were suspended, for when the heart has so far recovered itself from the immediate effects of the strain that the pulse-rate has fallen to normal any slight exertion or emotion will bring the palpitation on again. The symptoms which I have - observed in these cases bave been chiefly the following.

Palpitation of the heart.-This is very distressing, and usually occurs on the slightest exertion or emotion. If not relieved by appropriate treatment it may possibly end in the permanent establishment of a "rapid heart." Dr. Bristowe has narrated a case in which paroxysms of extreme rapidity of the heart's action were probably initiated in a boy eight years of age from physical exertion in a paperchase. This ultimately became a case of confirmed "rapid heart," and ended in sudden death at the age of nineteen years.

Shortness of breath.-This usually accompanies the palpitation and comes on when the patient exerts himself even in a slight degree.

Sensation of sinking at the epigastrium.-In certain of my cases this has been one of the most prominent symptoms.

Subjective sensations in the region of the heart.-The patient is conscious of the heart's action, and often feels as if it were going to stop.

Intermittency of the heart's action.-I believe that I bave traced the origin of this condition in several cases to a temporary dilatation of the heart as the result of hillclimbing.

Anginoid symptoms.-Two of my cases complained chiefly of pain in the cardiac region, coming on in paroxysms, running down the left arm, and accompanied by a sense of suffocation and impending death. They both completely recovered under appropriate treatment.

These, then, are some of the possible evils of excessive cycling. On the other hand, we have the undoubted fact that in moderation and under proper conditions it is one of the most health-giving forms of exercise. In established heart disease, strange as it may seem, it is one of our most potent remedial measures. Commencing with the lowest gearing for the shortest periods and aloug level roads, carefully graduated cycling is able to establish that compensatory hypertrophy which alone can enable the victims of valvalar disease of the heart to live in comfort and usefulness. For this purpose I prescribe it largely.

Let us now turn to preventive measures and consider some precautions against the dangers of this fascinating sport. I would lay stress upon the following points :-

1. The use of a low gear.-This bas been already described.

2. The upright position in riding. - The stooping posture, so habitual to the modern cyclist, by contracting the chest prevents the proper expansion of the lungs, and by interfering with the aeration of the blood causes the condition of breathlessness to come on quicker.

3. Adequate fond when riding, and the avoidance of muscle poisons such as beef-tea.-A badly nourished muscle gives way sooner than one which is well fed. As I have pointed out in a previous paper, it is probable that the digestive power of the stomach is inhibited during riding. From this it follows that the ordinary food taken by the cyclist on the track or road is not digested, and does not provide bim with energy. In the paper alluded to I advocated the use of peptonised gruel or soup.

4. The cyolist must avoid preparations of kola and coca.-These by numbing the sense of weariness enable injuriously excessive work to be done almost without the knowledge of the rider.

5. On no account should the cyolist continue riding after he has commenced to feel short of breath, or when there is the slightest sensation of uneasiness in the chest.-This simple precaution is one which cannot be too earnestly recommended. Queen Anne-street, W.

\section{SUCCESSFUL OVARIOTOMY ON A PATIENT} IN HER EIGHTY-SEVENTH YEAR

UPON WHOM OVARIOTOMY HAD ALSO BEEN PERFORMED WHEN SHE WAS NEARLY EIGHTY YEARS OF AGE.

\section{BY E. MATTHEWS OWENS, L.R.C.P. EDIN.,} M.R.C.S. ENG.

MANY of the readers of THE LANCET who are interested in gynæcological matters will perhaps remember that a case was recorded by Mr. Lawson Tait at a meeting of the Gynæco. logical Sjciety in 1888 of a patient seventy-nine years and ten months who had been successfully operated upon by me for a large parovarian oyst by abdominal section. The case remained for some time as the oldest on record; but as time went on it was exceeded. Dr. Herbert Spencer ${ }^{1}$ records one in a patient eighty-two years and two months old. Also there is one by $\mathrm{Mr}$. Bush ${ }^{2}$ in a patient in her eighty-fifth year. But any case in a patient over eighty years of age must still be considered as worth recording; otherwise Dr. Heywood Smith would not publish one in a patient eighty-one years of age. ${ }^{3}$ Hence it is that I feel rather prond in being able to put on record a successful ovariotomy in a patient in her eighty-seventh year.

A married woman who bad been operated upon by me in December, 1887, being then aged seventy-nine years and ten months, remained quite well until the middle of 1893, when she noticed that ber abdomen was swelling. It gradually increased until it prevented her from taking ezercise. I was asked to see her in February, 1894, and diagnosed a fibro cystic tumour of the ovary, evidently growing rapidly. From the history given me I am afraid I rather ridiculed any operative interference; but not so the patient, for when she distinctly understood that it was an ovarian tumour she called her family together, they acting as jury and she as judge, and the verdict being "that as her life had become a burden through the size of the tumour, and she had survived one operation, therefore she saw no reason why she should not survive a second." I was sent for, told the decision, and requested to operate as soon as possible, she and her friends accepting all responsibility. Under the circumstances I thought it well not to lose any time, so three days after the decision was arrived at-viz, on May 3rd, 1894 (that is, six years and three months since she had been previously operated upon, her age being thus exactly eighty-six years and one montb)I operated at her own house, Dr. Lilian Cooper giving chlorcform. The operation was quite simple, but as in 1887 the parovarian cyst had been removed from the left side it was a fair deduction to make that the present tumour wonld arise from the right side. Therefore I made my incision to the right side of the 1887 one, but on opening the peritoneum I had to my astonishment to get over to the left side to reach the pedicle of the tumour, which proved to be, as diagnosed, fibro-cystic. The patient made an excellent recovery, 'without a bad symptom as

$$
1 \text { Brit. Med. Jour., Dec. 9th, } 1893 .
$$$$
3 \text { THE LANCET, June 30th, } 1894 .
$$ 